\title{
AÇÃO DISCURSIVA DO BIBLIOTECÁRIO ESCOLAR
}

\section{ACCIÓN DISCURSIVA LA BIBLIOTECARIA DE LA ESCUELA}

\author{
Simone Alves da Silva - si.librarian@gmail.com \\ Mestre em Ciência da Informação no Instituto Brasileiro de \\ Informação em Ciência e Tecnologia (IBICT). Bibliotecária da \\ Biblioteca Central do Colégio Pedro II.
}

Clóvis Ricardo Montenegro de Lima - clovis.mlima@uol.com.br Pós-doutor em Ciência da Informação pelo Instituto Brasileiro de Informação em Ciência e Tecnologia (IBICT). Pesquisador adjunto

IBICT.

\begin{abstract}
RESUMO
Introdução: O presente estudo tece algumas considerações sobre a biblioteca e a prática profissional do bibliotecário escolar. Com base nisso, apresenta reflexões acerca do seu agir no processo de ensino-aprendizagem em uma perspectiva comunicativo-discursiva.

Objetivo: Refletir a prática do bibliotecário escolar à luz das Teorias do Agir Comunicativo e do Discurso de Jürgen Habermas.

Metodologia: Estudo bibliográfico das obras de Jürgen Habermas e revisão de literatura que centra-se na prática do bibliotecário escolar.

Resultados: Devido a emergência de uma racionalidade comunicativa e pedagógica na prática do bibliotecário escolar, as teorias de Jürgen Habermas se constituem em um importante referencial teórico, pois podem promover o desenvolvimento de estruturas cognitivas e sócio-afetivas individuais, ética e política, bem como a criação de solidariedade e a formação de identidades sociais permitindo que a comunidade escolar ascenda a novos patamares de integração social.

Conclusões: Aponta para a necessidade de o bibliotecário refletir a sua prática no ambiente educacional, tendo em vista que este profissional geralmente é visto como guardião de livros, ordenador e detalhista técnico. Indica a importância de se desenvolver novos estudos sobre essa temática que envolva outros elementos de análise permitindo assim avaliações mais detalhadas.
\end{abstract}

Palavras-chave: Bibliotecário escolar. Habermas. Agir comunicativo. Discurso. 


\section{INTRODUÇÃO}

Na sociedade contemporânea a educação é a chave para o desenvolvimento e para o enfrentamento das desigualdades, uma vez, que nesse contexto não basta ter o domínio da tecnologia, mas também a habilidade para transformar o imenso volume de informações em conhecimento. O papel da educação é desenvolver a habilidade das pessoas de processar informações, ampliando suas potencialidades reflexivas, críticas, criativas, comunicativas e expressivas, capacitando-as para lidar com diversas situações e tomar decisões na resolução de problemas.

A biblioteca escolar, como instituição vinculada ao sistema educacional, enquadrase nesse contexto. Dessa forma, dela são requeridas novas estratégias de ação que favoreçam sua adequação à nova realidade e permitam, por exemplo, acompanhar os avanços tecnológicos, desenvolver iniciativas que atendam as demandas das pessoas, integrando processos de ensino-aprendizagem que privilegiem a promoção da interação e colaboração criativa no ambiente educacional.

Essas novas demandas levam o bibliotecário a refletir sobre suas atribuições, habilidades e responsabilidades no âmbito educacional, pois o seu agir não deve se restringir ao enfoque técnico, mas incentivar a interação efetiva entre os indivíduos, viabilizando a criação e a manutenção de canais de comunicação abertos e espaços de socialização do conhecimento no âmbito da escola.

Assim, partindo-se desses pressupostos, o objetivo geral deste estudo é proceder a um esforço inicial de refletir o agir do bibliotecário escolar no processo de ensinoaprendizagem à luz das Teorias do Agir comunicativo e do Discurso de Jürgen Habermas, uma vez que estas favorecem o desenvolvimento de processos de aprendizagem por meio da intersubjetividade entre sujeitos capazes de falar e de agir.

Dessa forma, a questão que norteia a pesquisa é "O agir comunicativo pode favorecer a efetiva inserção do bibliotecário escolar no processo de ensinoaprendizagem?"

Nessa perspectiva, acredita-se que o bibliotecário pode assumir a importante função de mediar o conhecimento e atuar no processo de ensino-aprendizagem como um orientador, um avaliador e um motivador, permitindo assim que a biblioteca se constitua em um espaço de efetiva interação e comunicação entre os atores da comunidade escolar e de produção de cultural e conhecimento. 


\section{AGIR COMUNICATIVO, DISCURSO E RECONSTRUÇÃO RACIONAL}

As estruturas da racionalidade, identificadas como: epistêmica, teleológica e comunicativa - se encontram no mesmo nível e são interligadas pela racionalidade discursiva. A racionalidade discursiva pressupõe, "[...] uma auto-relação reflexiva da pessoa com o que ela pensa, faz e diz; por meio das auto-referências correspondentes, essa capacidade se entrelaça com as estruturas racionais centrais do saber, da atividade orientada a fins e da comunicação." (HABERMAS, 2004, p. 102).

A busca de Habermas por uma forma de racionalidade que não ficasse restrita à unilateralidade da dimensão cognitiva e que não se preocupasse apenas com a questão da verdade, mas também com a justiça e a sinceridade desvinculando-se da racionalidade da dominação, resulta no desenvolvimento da racionalidade comunicativa, que corresponde à comunicação lingüística voltada ao entendimento (SIEBENEICHLER, 2003).

Siebeneichler (2003) aponta as características da racionalidade comunicativa a partir dos processos comunicativos, que compreendem: comunicação como ação social; coordenação através de atos de fala; variedade de ações comunicativas. A comunicação como ação social, tem como princípio a definição de que toda ação é determinada para um fim racional que o sujeito estabelece. No entanto, Habermas amplia esta definição ao considerar que a orientação da ação racional não se efetiva apenas pela realização do sujeito, mas também pela comunicação intersubjetiva.

A racionalidade comunicativa é orientada pelos atos de fala que possuem uma força coordenadora de ações que decorre dos seus elementos comunicativos e ilocucionários, o que se justifica pelo fato do componente ilocucionário ser formado por verbos performativos pelos quais se fundamentam as pretensões de validade. Siebeneichler (2003, p. 67) afirma que estes elementos são determinantes para que

[...] o falante e o ouvinte entrem numa relação intersubjetiva, a qual, como já sabemos, repousa na base de pretensões de validade que têm de ser levantadas, de deveres de justificação que têm de ser assumidos e da pressuposição de uma possível união verdadeira no discurso.

A última característica da racionalidade comunicativa refere-se à pluralidade de ações comunicativas decorrentes dos três tipos de atos de fala, a saber: os atos constativos caracterizam as ações de conversação; os regulativos determinam o agir 
comandado por normas; por fim, os expressivos caracterizam o agir dramatúrgico (SIEBENEICHLER, 2003).

Para trazer à tona o conteúdo normativo dos processos de comunicação e as formas de aquisição e utilização do conhecimento resultante das interações intersubjetivas no mundo da vida, Habermas vai buscar na teoria sociológica da ação os mecanismos de coordenação de ações para estabelecer os padrões de interação. Na sua concepção, a interação se efetiva por meio das ações que se encontram coordenadas de acordo com regras. Tais regras são consubstanciadas no mútuo acordo, que para Habermas (2010, p. 139),

[...] significa que os intervenientes aceitam um saber como válido, ou seja, como intersubjetivamente vinculativo. Só então um conhecimento comum, na medida em que contenha componentes ou implicações relevantes para as consequências da interação pode assumir funções de coordenação de ações.

Essas funções de coordenação da ação guiam-se pela força ilocucionária dos atos de fala, determinando assim o modo de ação dos atores em uma interação, a saber: a ação teleológica, estratégica, normativa, dramatúrgica e comunicativa.

A ação teleológica objetiva a concretização de fins ou realização de um plano de ação onde apenas um ator está envolvido. Este, por sua vez, atinge seu objetivo escolhendo os meios promissores de êxito e aplicando-os de forma apropriada. Essa estrutura teleológica constitui os demais conceitos de ação, todavia, esses conceitos de ação distinguem-se segundo a forma de coordenação das ações individuais. Desse modo, os participantes da interação podem adotar uma atitude orientada para o êxito ou para o entendimento (HABERMAS, 2010).

$\mathrm{Na}$ ação estratégica as forças ilocucionárias dos atos de fala não assumem uma função coordenadora da ação, a linguagem adquire uma concepção de manipulação instrumental, por meio da qual os sujeitos impõem sua convicção, manipula outros sujeitos para atingir seus próprios fins transformando-se em um simples meio de informação (GONZALEZ DE GÓMEZ, 2009; PINZANI, 2009). A coação é a sua força motriz, por essa razão pode-se chegar ao consenso, mas não à um acordo mútuo, porque este não pode ser imposto, "[...] seja de forma instrumental, por intervenções imediatas sobre a situação da ação, ou de forma estratégica, pela influência calculada em função do êxito sobre as atitudes do parceiro." (HABERMAS, 2010, p. 140). 
A ação regulada por normas, na concepção de Habermas (2010, p. 145), é aquela em que "[...] os membros de um grupo social orientam a sua ação por valores comuns." Nesse modelo o entendimento visa atualizar um acordo pré-existente.

A ação dramatúrgica no entendimento de Habermas (2010, p. 142),

[...] apoia-se na relação consensual entre um intérprete que se põe em cena, causando uma determinada impressão e o seu público, e a interação mediada pela linguagem requer o estabelecimento de consensos, seja pela adoção interpretativa de papéis e a sua projeção criativa, ou por processos de interpretação cooperativos.

A ação comunicativa se orienta por conviçcões intersubjetivamente partilhadas que vinculam mutuamente os participantes de uma interação em direção ao entendimento sobre algo no mundo. $O$ entendimento se desenvolve a partir da relação reflexiva atormundo, na qual os participantes do agir comunicativo colocam demandas por meio de pretensões de validade que podem ser aceitas ou refutadas (GONZÁLEZ DE GÓMEZ, 2009).

A contraposição entre ação comunicativa e estratégica constitui ponto central da teoria social de Habermas, uma vez que permite explicar a forma de reprodução da vida humana que pode estabelecer-se por meio de ações de êxito ou de entendimento. $\mathrm{Na}$ primeira, as ações sociais são reguladas pela competição por dinheiro ou poder, neste caso a sociedade se apresenta sob uma ordem instrumental (HABERMAS, 2010). $\mathrm{Na}$ segunda, devido a concepção de integração social que decorre da força consensual do entendimento lingüístico, e por meio da qual as energias de ligação da própria linguagem tornam-se efetivas para a coordenação das ações, faz com que a ação comunicativa se constitua no ponto de engate para a solidariedade social formando uma sociedade mais justa (HABERMAS, 2012).

O agir comunicativo, segundo Pinzani (2009, p. 98) se configura a partir de processos de comunicação que podem acontecer em três níveis, a saber:

[...] a relação do sujeito do conhecimento com um mundo de eventos ou fatos. [...] a relação do sujeito prático, que age e está envolvido em interações com os outros. [...] a relação do [...] sujeito com a sua própria natureza, com a sua subjetividade e com a subjetividade dos outros.

Esses processos de comunicação referem-se aos Três Mundos de Popper: objetivo, social e subjetivo. O primeiro corresponde à construção do conhecimento 
verdadeiro sobre o mundo de fatos e estados de coisas. O segundo, refere-se à critica ou resgate das normas, valores, significados compartilhados que orientam as interações. $O$ último ocupa-se da crítica ou do resgate da sinceridade da subjetividade do sujeito e do seu projeto individual de vida (BANNELL, 2006).

Habermas (2012) afirma que as pretensões de validade se caracterizam por diferentes categorias de saber: verdade proposicional, correção normativa e veracidade subjetiva. Na medida em que essas demandas são problematizas e a correspondente pretensão de validade é desafiada, existe a possibilidade de se entrar na forma reflexiva do agir comunicativo, que o teórico denomina de Discurso, que visa questionar a validade da pretensão levantada pela argumentação.

Em um procedimento argumentativo ideal, todos os integrantes do discurso participam, todas as vontades subjetivas são expressas, todas as críticas e ponderações são consideradas, todas as consequências práticas são antecipadas e todos os efeitos colaterais de uma possível ação são pesados, conforme descrito por Habermas (2003, p.120),

[...] os participantes da interação unem-se através da validade pretendida de suas ações de fala ou tomam em consideração os dissensos constatados. Através de suas ações de fala são levantadas pretensões de validade criticáveis, as quais apontam para um reconhecimento intersubjetivo. A oferta contida num ato de fala adquire força obrigatória quando o falante garante, através de sua pretensão de validade situada, que está em condições de resgatar essa pretensão, caso seja requerido, empregando o tipo correto de argumento.

A ética do discurso pressupõe alguns aspectos, a saber: esfera pública; distribuição equitativa de direitos de comunicação; a competência comunicativa dos integrantes do grupo; situações dialógicas ideais, livres de coerção e violência; autenticidade; e um sistema linguístico elaborado que permita por em prática o discurso teórico e prático. Habermas (2003, p. 113) identifica estes aspectos como a base de validade do discurso que implica em quatro condições essenciais para se participar do processo discursivo e suas respectivas pretensões de validade universais.

A reconstrução racional centra-se na ideia de reflexão, não como no sentido de reflexão transcendental e monológica da filosofia da consciência, mas como um meio que busca alcançar o sentido oculto de um texto ou comunicação sistematicamente distorcida. Assim, a reflexão apresenta-se como uma 
[...] força esclarecedora, [que pode] revelar-nos, no âmbito de uma crítica da ideologia, aquilo que antes estava oculto, atrás de nossas costas, determinando-nos ideologicamente: opiniões, preconceitos ingênuos, visões de mundo. Ela é capaz de detectar os contextos de ação sistematicamente distorcidos, os elementos não entrevistos de coação e de dominação (SIEBENEICHLER, 2003, p. 83).

O conceito de reflexão adotado por Habermas, segundo Siebeneichler (2003), é complexo e envolve três concepções distintas, a saber: a) reflexão como forma de fundamentação racional transcendental de todo saber teórico possível e de toda a ação moral possível, trata-se de uma reflexão sobre as condições de possibilidade das competências do sujeito que conhece, fala e age; b) reflexão como dissolução crítica, levado a cabo pela consciência, auto-crítica, que produz a libertação em relação a uma objetividade aparente; c) reflexão no sentido de psicanálise freudiana, trata-se de uma ideia de auto-crítica no nível subjetivo, estando relacionada à experiência reflexiva do sujeito que se encontra em um estado de falsa consciência sobre si mesmo, devido a padrões de percepção e de ação restringidos através de coação.

A reconstrução racional é o elemento principal da teoria da pragmática universal de Habermas (1996, p. 9), cuja função "[...] é identificar e reconstruir condições universais de possível compreensão mútua (Verständigung ${ }^{1}$ )", dentro de um sistema de condições, categorias e regras que condicionam um falante competente a construir e utilizar conhecimentos, bem como agir racionalmente. Neste sentido, é fundamental que o individuo consiga estabelecer uma comunicação que acontece em dois níveis (simples e metacomunicação).

As expressões linguísticas são formadas por enunciados performativos e por enunciados com conteúdo proposicional (dependente do primeiro). O enunciado performativo determina a relação intersubjetiva entre falante e ouvinte; o proposicional serve para comunicar coisas ou circunstâncias. A construção de enunciados performativos e proposicionais, por sua vez, depende que os atores de uma interação disponham de competência linguística, uma vez que esta corresponde à capacidade de dominar o sistema de regras e normas próprio de uma comunidade e de aplicá-las refletidamente no seu agir cotidiano (PINZANI, 2009).

\footnotetext{
${ }^{1}$ A palavra Verständigung é ambígua: no sentido mais restrito indica que dois participantes de uma comunicação compreendem da mesma forma uma determinada expressão linguística. No sentido mais amplo, refere-se a existência de um acordo entre esses participantes no que se refere ao acerto de uma expressão de uma base normativa mutuamente reconhecida (HABERMAS, 1996).
} 
Dispondo de tal competência linguística, os participantes de uma interação conseguem estabelecer uma comunicação em dois níveis: a comunicação simples e a metacomunicação - princípio fundamental para se alcançar a compreensão mútua. A comunicação simples refere-se a coisas ou circunstâncias que somente pode estabelecerse se houver simultaneamente uma metacomunicação sobre o sentido do uso do enunciado proposicional (PINZANI, 2009). Dessa forma, em qualquer situação de entendimento, é fundamental que os indivíduos estabeleçam esses dois níveis de comunicação.

A habilidade de estabelecer uma comunicação em dois níveis é denominada por Habermas de competência comunicativa que se constitui "[...] na reconstrução do sistema de regras que um falante competente tem de dominar se pretender fazer jus ao postulado da simultaneidade entre o nível comunicativo e metacomunicativo da comunicação." (SIEBENEICHLER, 2003, p. 92). Apoia-se também no paradigma da interpretação da hermenêutica macroscópica de Garfinkel, a qual se refere à habilidade de questionamento e julgamento racional das pretensões de validade do saber utilizado pelos participantes de um diálogo, sendo assim decisivo para a interpretação e compreensão mútua, logo para uma comunicação isenta de obstáculos (SIEBENEICHLER, 2003).

O princípio da reconstrução racional, proposto por Habermas em suas teorias, orienta-se na teoria de Wittgenstein, referindo-se, assim como as ciências hermenêuticas, a um universo de objetos estruturados simbolicamente: fatos culturais, formações linguísticas, conceitos, critérios, regras e esquemas (HABERMAS, 1996; SIEBENEICHLER, 2003). Este princípio apoia-se também na ideia que os indivíduos que produzem as configurações simbólicas, aplicam seu sistema de regras sem consciência de sua existência. Nesse sentido, o princípio reconstrutivo da pragmática universal consiste em

[...] explicitar sistematicamente, através de categorias apropriadas, as estruturas profundas e os elementos de um "saber de regras" pré-teórico, intuitivo, que os sujeitos têm de dominar praticamente quando entram numa situação de interação através da fala (SIEBENEICHLER, 2003, p. 92).

Esse conhecimento pré-teórico e implícito do sistema de regras linguístico de um falante é definido como know-how. No momento em que um intérprete compartilha e compreende o conteúdo desse conhecimento implícito do falante, transformando-o em 
conhecimento específico, trata-se de um know-that. Este processo representa a função da reconstrução racional, a qual funciona como um sistema de avaliação do saber préteórico, como salienta Habermas (1996, p. 28-29),

Com efeito, as propostas reconstrutivas são orientadas para os domínios do conhecimento pré-teórico, ou seja, não para uma qualquer opinião implícita mas sim para um conhecimento prévio e intuitivo já comprovado. A consciência de regras dos falantes competentes funciona como um tribunal de avaliação, por exemplo, no que se refere à gramaticalidade das frases. [...] Quando o conhecimento pré-teórico, a ser reconstruído, expressa uma capacidade universal e uma competência (ou subcompetência) geral cognitiva, linguística ou interativa, então aquilo que começou como uma explicação do significado adquire um objetivo de reconstrução de competências específicas.

\section{EDUCAÇÃO E EMANCIPAÇÃO}

Apesar da educação não ser o tema central da teoria de Habermas, acredita-se que a racionalidade presente no agir comunicativo se configure em uma abordagem que pode trazer importantes contribuições na construção de uma educação que promova a autonomia e o esclarecimento, pois se constitui na possibilidade "[...] de uma ação emancipatória na escola, a partir da constituição de um sujeito, cuja racionalidade não seja nem instrumental nem a do procedimento." (PRESTES, 1996, p. 11).

Partindo desse pressuposto, Habermas articula a sua teoria da racionalidade comunicativa e a Teoria do Agir Comunicativo com o conceito de esclarecimento que é um importante fator no processo histórico da liberdade e da emancipação do homem, constituindo-se em elemento chave no processo de aprendizagem. A importância do esclarecimento é reforçada ao longo da história do pensamento moderno, como também na sociedade contemporânea, por envolver conceitos que visam: justiça, liberdade, emancipação, ação, sujeito, igualdade, totalidade e humanidade libertada (SIEBENEICHLER, 2003).

Nesse sentido, o esclarecimento não tem somente o papel de ensinar aos homens os direitos e os deveres de fazer uso da razão sem limites e de tomar uma decisão ética inteiramente livre, mas enquanto movimento histórico e processo de emancipação pode modificar a estrutura da consciência, das instituições econômicas, jurídicas, da arte, da religião e dos costumes através da interação mediada pela linguagem (SIEBENEICHLER, 2003). 
Para construir o seu conceito de esclarecimento Habermas se baseia nesses princípios e na concepção de esclarecimento de Kant, Hegel e Marx que ensinam a utilização da razão e tentam estabelecer uma conexão entre liberdade, emancipação e história (SIEBENEICHLER, 2003). No pensamento desses teóricos, o esclarecimento se constitui no:

[...] trabalho crítico da razão, que passa a analisar tanto o estado de dominação, como o de liberdade conquistada pelo homem num determinado momento de sua história, como ainda o dos objetivos a serem atingidos no futuro (SIEBENEICHLER, 2003, p. 12).

Habermas acredita no potencial emancipatório de um esclarecimento complexo, baseado no racionalismo lógico, normativo, social, estético e subjetivo. No entanto, o teórico prefere seguir o contradiscurso da filosofia do esclarecimento prático moderno que busca analisar os limites e a ignorância do esclarecimento. Embora Habermas siga a linha do esclarecimento prático, convém salientar que o teórico apoia seu pensamento esclarecedor na relação entre racionalidade e o processo histórico orientado à emancipação (BANNELL, 2006; SIEBENEICHLER, 2003). Seu objetivo é desenvolver a emancipação humana através do esclarecimento e do processo de racionalização, cuja finalidade é "[...] resgatar e liberar a pretensão de razão anunciada nas estruturas teleológicas e intersubjetivas da reprodução social." (BANNELL, 2006, p. 18), o que favorece a formação racional da identidade do indivíduo e da coletividade.

Com isso, Habermas faz uma distinção entre emancipação em relação à natureza exterior e em relação às formas de dominação social e política. Segundo Aragão (2006), a primeira se concretiza através do progresso técnico e a segunda por meio de novos níveis de reflexão, nos quais os sujeitos assumem posições de aceitação ou recusa de normas e formas de identidade vigente.

Assim, a educação na perspectiva habermasiana visa promover um processo de formação de sujeitos capazes de linguagem e de ação. Esse processo de formação se constitui em uma série irreversível de estágios de desenvolvimento discretos e cada vez mais complexos que conduzem os sujeitos a novos níveis de reflexão, isto é, a aprendizagem, o que the permite ganhar um grau sempre maior de autonomia, assim como satisfazer determinadas exigências levantadas pelo seu ambiente natural e social (PINZANI, 2009). 
Esses estágios dos processos de aprendizagem relacionam-se com as quatro categorias da racionalidade da ação: ação teleológica (estratégica), ação normativa, ação dramatúrgica e o agir comunicativo. Essas ações podem ser planejadas, executadas e avaliadas segundo o grau de racionalidade empregada na ação, o que determina a sua validade e eficácia (BANNELL, 2006). Outra questão salientada por Bannell (2006), diz respeito aos pressupostos ontológicos de cada modelo de ação que são cada vez mais complexos exigindo que a racionalidade seja empregada na mesma proporção, elevando o nível de descentração do indivíduo.

$\mathrm{Na}$ ação teleológica a racionalidade é avaliada segundo critérios de validade e eficácia. O primeiro refere-se às crenças do agente sobre o mundo objetivo representadas nos conteúdos proposicionais dos proferimentos que podem ser verdadeiras ou falsas. $\mathrm{O}$ segundo, diz respeito à capacidade do agente em modificar ou não o mundo de acordo com seus desejos e intenções podendo ser eficaz (racional) ou ineficaz (irracional). A aprendizagem se dá no plano cognitivo de percepções e crenças do indivíduo que podem estar condizentes ou não com a realidade em que está inserido (BANNELL, 2006).

$\mathrm{Na}$ ação normativa o agente estabelece uma relação reflexiva com o mundo objetivo e o mundo social. É nesse contexto que se determinam as normas que serão aceitas como válidas pelos atores e aquelas que imprimem legitimidade às interações $e$ relações interpessoais entre os agentes. A racionalidade da ação normativa pode ser avaliada de duas formas: se há conformidade das ações com as normas existentes ou se as normas condizem com os interesses dos membros da comunidade e merecem aceitação (BANNELL, 2006). A aprendizagem no contexto normativo "[...] refere-se à internalização de valores e à formação de um complexo motivacional adequado ao contexto normativo existente [...]", bem como as relações interpessoais. (BANNELL, 2006, p. 44).

É importante salientar, que neste modelo de ação existe a possibilidade de uma aprendizagem mais complexa por não contar somente com a formação do complexo cognitivo da ação teleológica, mas também com a formação do complexo motivacional ${ }^{2}$. Segundo Bannell (2006, p. 44), esse processo de aprendizagem visa:

[...] avaliar se as normas consideradas legítimas, aqui e agora, realmente satisfazem seus interesses generalizáveis, por meio de um processo discursivo de interpretação das suas necessidades. Nesse caso, a força

${ }^{2}$ Complexo motivacional refere-se ao fato do agente poder adotar uma atitude em relação ao mundo objetivo e outra atitude em relação ao mundo social (BANNELL, 2006). 
motivadora das normas existentes pode enfraquecer, desencadeando uma situação em que novas necessidades são interpretadas e desenvolvidas em novas disposições, por meio de processos de aprendizagem.

No caso da ação dramatúrgica, é estabelecida uma relação com o mundo subjetivo, que na concepção de Habermas (2012, p. 91) representa a "[...] totalidade de experiências subjetivas a qual o ator tem, em relação aos outros, um acesso privilegiado." No mundo subjetivo são considerados os desejos e sentimentos, que são experiências primárias e manifestações da necessidade humana, apesar disso, os sentimentos devem ser compreensíveis de tal modo, que outros membros que compartilham a mesma tradição cultural possam reconhecer suas próprias necessidades nas interpretações.

Nesse contexto, a racionalidade é avaliada segundo a coerência entre os desejos e sentimentos expressos pelo agente e os padrões culturais compartilhados pela comunidade em que está inserido. Desse modo, a aprendizagem se dá pelo ajuste entre sentimentos e os padrões culturais compartilhados; pela maneira de expressar a natureza interior e as experiências internas que temos de fato; e por fim, pelo ajuste das nossas ações com a expressão dos sentimentos (BANNELL, 2006).

Como o agir comunicativo visa a uma relação reflexiva com o mundo objetivo, social e subjetivo, possibilita a interação orientada à busca do entendimento mútuo e a coordenação das ações. Desse modo, constitui-se na forma de ação com o maior potencial de aprendizagem, seja no nível individual ou coletivo promovendo a racionalização da sociedade e consequentemente seu desenvolvimento.

$\mathrm{Na}$ esfera do agir comunicativo ainda pode haver um nível mais elevado de entendimento (o consenso) que corresponde à passagem para a esfera do discurso (a forma reflexiva do agir comunicativo) que permite estabelecer acordos verdadeiramente racionais, os quais se diferem do consenso fático que se dá no nível da comunicação quotidiana. Tal procedimento racional possibilita a avaliação crítica das relações de forças e das posições assumidas em relação aos mundos objetivo, social e subjetivo, que na concepção de Habermas compõem o mundo da vida, conferindo ao homem um progresso na autonomia da ação, a liberdade da dominação política e social e consequentemente a formação da sua identidade e da sua consciência moral. (ARAGÃO, 2006; HABERMAS, 1996).

A linguagem assume assim, um importante papel no processo de emancipação da humanidade devido ao seu caráter social, uma vez que atua como medium universal para comunicação. Siebeneichler (2003, p. 50) ressalta que a comunicação linguística, 
[...] constitui, pois uma "força" a qual sujeitos devem a sua maioridade. Porque a comunicação é a figura de uma vida verdadeira. A interrupção da comunicação é a figura de uma vida falsa, porque não apenas faz silenciar o falante, mas torna-se sem linguagem, isola-o na solidão. A comunicação constitui o equilíbrio, o balanceamento salvador entre a solidão sem linguagem e a alienação, entre o sacrifício da individualidade e o isolamento daquele que se tornou só.

A maioridade alcançada com a comunicação linguística, isto é, a capacidade de construir o saber a partir da crítica racional e da competência comunicativa resulta de processos de aprendizagem, que na opinião de Habermas (2003), é indispensável à evolução social. Na visão habermasiana a aprendizagem se baseia nas seguintes suposições:

[...] a suposição de que o saber em geral pode ser analisado como um produto de processos de aprendizagem; depois, que o aprendizado é um processo de solução de problemas no qual o sujeito que aprende está ativamente envolvido; e, finalmente, que o processo de aprendizagem é guiado pelos discernimentos dos próprios sujeitos diretamente envolvidos nesse processo (HABERMAS, 2003, p. 50).

Essas suposições, que fundamentam o processo de aprendizagem, correspondem à capacidade da abstração reflexionante que leva o sujeito à descentrações progressivas. O conceito de abstração reflexionante se refere a

[...] processos mais gerais de equilibração e possui diferenciação de graus e natureza. Conforme indica a etimologia, abstrair significa "descolar", "arrancar", extrair algo de alguma coisa. O sujeito por uma ação intelectual representativa "retira" dos objetos aquilo que seu esquema de assimilação permite retirar. Os esquemas, por sua vez, dependem da totalidade das experiências anteriores, das abstrações realizadas (PRESTES, 1996, p. 43-44, grifo do autor).

O conceito de descentração corresponde ao "[...] sistema de coordenação [do homem] que permite por em correspondência relações diferentes." (HERMANN, 2012, p. 3). Uma consciência descentrada tem a habilidade de estabelecer relações complexas ao passo que o conhecimento anterior dá lugar a um conhecimento novo, conduzindo o homem a níveis mais elevados de racionalidade e de evolução social.

No entendimento de Hermann (2012), o processo de aprendizagem baseado no agir comunicativo pode contribuir na promoção do desenvolvimento de estruturas cognitivas e sócio-afetivas individuais, permitindo que as sociedades ascendam a novos 
patamares de integração social. Além disso, os níveis atingidos de descentramento e de racionalização favorecem o desenvolvimento de potenciais cognitivos, morais e interativos que orientam o agir e as demandas sociais.

Neste sentido, é necessário manter um trabalho crítico sobre a responsabilidade da instituição e dos profissionais que nela atuam, com o fim de organizar critérios de racionalidade capaz de produzir entendimento e criar estruturas que objetivem:

- promover a capacidade discursiva daqueles que aprendem;

- promover condições favoráveis a uma aprendizagem crítica do próprio conhecimento científico;

- inocular a semente do debate, considerando os níveis de competência epistêmica dos alunos;

- promover a discussão pública sobre os critérios de racionalidade subjacentes às ações escolares, seja através dos conhecimentos prevalentes no currículo, seja pela definição de políticas públicas que orientem a ação pedagógica;

- estimular processos de abstração reflexionante, que permitam a níveis superiores a crítica da sociedade e dos paradoxos de racionalização social e, a partir daí, realizar processos de aprendizagem, não só no plano cognitivo, como também no plano político e social;

- promover a continuidade de conhecimentos e saberes da tradição cultural que garantam os esquemas interpretativos do sujeito e a identidade cultural (PRESTES, 1996, p. 107).

A educação pode ativar as estruturas da interação e da comunicação para produzir o entendimento e o compromisso ético na ação dos sujeitos, tornando-os mais esclarecidos e emancipados. Além disso, pode produzir uma prática educativa sem ingenuidades e voluntarismos formando um público capaz de refletir criticamente e atuar em discussões, o que pode transformar as estruturas produtivas, normativas e pessoais necessárias à reprodução da vida humana.

\section{DO “CONFORMISMO" AO AGIR DISCURSIVO: REFLEXÕES SOBRE A PRÁTICA DO BIBLIOTECÁRIO ESCOLAR}

Morigi e Bonotto (2004, p. 148) destacam que o esforço para compreender os elementos que compõem as representações da comunidade escolar em relação à biblioteca e ao bibliotecário permite 
[...] atualizar e reordenar as nossas impressões e as imagens sobre a realidade presente $e$, assim, provocar modificações nas nossas representações sobre o tempo passado. Por esse motivo, a partir das ideias no presente, podemos reconstruir as impressões sobre o passado. Ao realizarmos essa operação, também atualizamos o nosso imaginário, o nosso acervo cultural.

Discutir as impressões e as imagens da biblioteca escolar e do bibliotecário na comunidade escolar é fundamental para repensar as suas bases e o agir biblioteconômico. A relevância do tema deve-se ao fato de muitas bibliotecas escolares ainda se encontrarem em estado de profunda precariedade em todos os aspectos (acervo, infra-estrutura, organização, etc.), constituindo-se em verdadeiros depósitos de livros "velhos", onde impera um "ar sombrio e silencioso" (CAMPELLO, 2012; FURTADO, 2012; MILANESI, 2002; MORO; ESTABEL, 2011; SILVA, 1995).

A biblioteca escolar, sobretudo a da escola pública, serve como lugar de passagem ou repouso profissional, onde professores por doença, velhice ou fastio pedagógico são encostados ou funcionários indisciplinados de outros setores são encaminhados. Diante de tantos problemas, a biblioteca escolar se encontra em um profundo silêncio: silenciam as autoridades, ignoram-na os pesquisadores, calam-se os professores, omitem-se os bibliotecários (FURTADO, 2012; SILVA, 1995).

Nesse cenário o primeiro contato com a biblioteca escolar geralmente é considerado desagradável, sinônimo de castigo, imposição, proibição e desconforto, tanto na visão do professor quanto na do aluno (CORRÊA et al., 2002; MILANESI, 2002; SILVA 1995). Ou então, na melhor das situações, a biblioteca é instituída como o lugar para pesquisar e copiar verbetes conforme orientação do professor, na qual o aluno cumpre uma obrigação para obter aprovação (CAMPELLO, 2012).

Essas concepções contradizem a missão da biblioteca escolar que é habilitar "[...] os alunos para a aprendizagem ao longo da vida e desenvolver sua imaginação, preparando-os para viver como cidadãos responsáveis." (INTERNATIONAL FEDERATION OF LIBRARY ASSOCIATIONS AND INSTITUTIONS/ORGANIZAÇÃO DAS NAÇÕES UNIDAS PARA A EDUCAÇÃO, A CIÊNCIA E A CULTURA, 2005, p. 4). Por conseguinte, a biblioteca não pode se restringir à tarefa técnica de organização e disponibilização da informação, sendo fundamental que

[...] ela exerça influência ativa e dinâmica no contexto envolvente, preocupando-se com a qualidade do seu acervo e dos seus serviços, com a origem e necessidades dos usuários, com a democratização dos seus 
espaços e com o planejamento de programas socioculturais (SILVA, 1993, p. 72).

Nesse sentido, a biblioteca deve ser um local de mediação na construção do conhecimento e o bibliotecário é o principal ator nesse processo, uma vez que ele é quem cumpre essa função. Mas, como se constrói o conhecimento em um local que não há discussão, debate e reflexão? O trabalho de mediar implica intervir, opinar, falar e participar, isto é, o bibliotecário deve refletir com o estudante acerca do tema questionado, ajudando-Ihe a construir um pensamento crítico, o que leva a transformação do seu estágio inicial do conhecimento.

Contudo, constata-se na literatura, que o termo mediar na prática biblioteconômica assume um sentido passivo de conformação e de neutralidade, uma vez que o bibliotecário é considerado por alguns autores o "intermediário" que interliga o usuário ao acervo, sendo sua função apenas organizar e disponibilizar, ou simplesmente incentivar a leitura, sem uma participação mais ativa (MORO; ESTABEL, 2011).

Dessa forma, é essencial repensar o agir do bibliotecário e eliminar o seu pensamento conformista. Para tanto, deve-se

[...] abandonar a lamúria e conferir a atuação [do bibliotecário] escolar uma característica mais agressiva. Basta de reclamar que o aluno e o professor não vão à biblioteca! Basta de lamentar que a biblioteca escolar está esquecida na escola! Mas vale desenvolver mecanismos que atraiam o professor e o aluno para a tarefa, eminentemente coletiva, de pensar e fazer uma biblioteca escolar atuante, eficiente e capaz de enriquecer 0 trabalho docente e a aprendizagem do aluno (SILVA, 1995, p. 62-63).

Somente assim, a biblioteca deixará de ser apenas um lugar que abriga livros e fechada em si mesma para se abrir à democratização do conhecimento, transformando-se em um organismo vivo e dinâmico propício à prática de ensino-aprendizagem e interação entre os sujeitos (CALDIN, 2005; MORO; ESTABEL, 2003). Nessa perspectiva, entendese a biblioteca escolar como:

[...] um centro de aprendizagem com uma participação direta em todos os aspectos do programa de educação com materiais de todo tipo, onde educadores, estudantes e usuários em geral podem redescobrir e ampliar os conhecimentos, desenvolver pesquisas, desenvolver aptidões para leitura, para opinar, para avaliar, assim como desenvolver todos os meios de comunicação de que dispõe o ser humano com o objetivo de assegurar uma aprendizagem total [...] (TOMÉ, 2009 apud MORO; ESTABEL, 2011, p. 18). 
Convém ressaltar que, independentemente da adoção de qualquer padrão ou execução de objetivos para a biblioteca escolar, a efetiva inserção desta no processo de ensino-aprendizagem depende de dois fatores: o primeiro é a definição de uma filosofia de aprendizagem subjacente que seja compartilhada por bibliotecário, professor e diretor da escola (KUHLTHAU, 1999). O segundo é o bibliotecário munir-se de conhecimentos pedagógicos, uma vez que este não dispõe de formação para atuar no aparelho escolar "[...] seja no âmbito da organização, do planejamento e da administração do acervo disponível, seja no que se refere ao trabalho de dinamização da leitura entre os alunos." (SILVA, 1995, p.14).

Nesse processo, torna-se, também fundamental, desenvolver as habilidades do pessoal da biblioteca, tendo em vista que o a biblioteca lida com diversos grupos de pessoas (pais, alunos, professores, administradores, profissionais de aconselhamento) que requerem habilidades especiais que podem ser assim definidas:

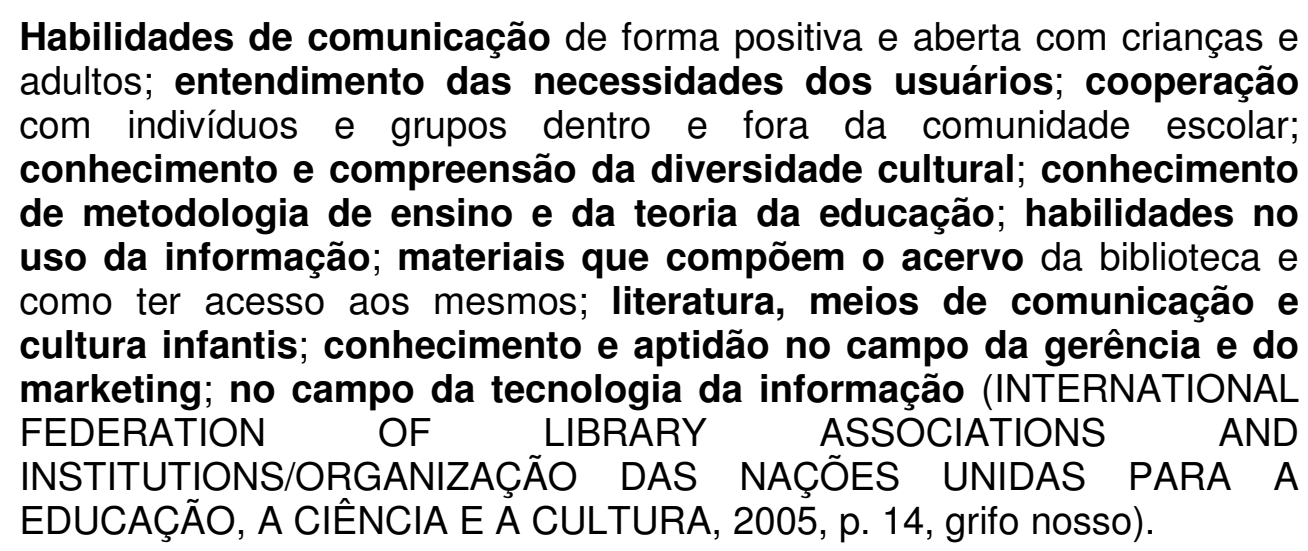

Assim, o bibliotecário deixa de ser um mero guardião, secular zelador de livros, severo, ordenador e detalhista técnico, cujas ações intimidam e cerceiam qualquer iniciativa de comunicação e discussão, para transformar-se em um educador como os outros, além de servir como apoio e complemento para os professores. O bibliotecário escolar será um educador, cuja disciplina é ensinar a aprender (MILANESI, 2002; VÁLIO, 1990).

Nesta pesquisa aponta-se não somente para a necessidade de aprofundar os estudos e a discussão sobre o papel do bibliotecário escolar, mas também para a importância de refletir o agir desse profissional sob a perspectiva comunicativo-discursiva. Pode-se fazer a reconstrução racional do agir do bibliotecário escolar, conferindo-lhe 
novas competências no processo de ensino-aprendizagem à luz das teorias do Agir comunicativo e do Discurso de Jürgen Habermas.

Nesse sentido, o exercício de reflexão sobre o agir do bibliotecário escolar, constitui um esforço inicial que pretende contribuir para a construção da identidade teórica e prática, dotando-o de parâmetros que podem inspirar ações educativas com enfoque na interação e na comunicação. A reflexão se fundamenta na teoria do Agir comunicativo, na qual se busca aspectos relacionados à aprendizagem, e também uma perspectiva de ação com foco na comunicação e na interação discursiva entre o bibliotecário e os atores da comunidade escolar.

Borba (2011) ressalta a importância de o bibliotecário assumir uma postura reflexiva da sua prática, pois tal atitude possibilita a ampliação de perspectivas que podem contribuir para o desenvolvimento de uma postura pedagógica com vistas a desenvolver a capacidade crítica, analítica, criativa e reflexiva do individuo por meio de processos de ensino-aprendizagem que privilegiem o enfoque comunicativo-discursivo. Assim, o entendimento do processo educativo, o planejamento e a avaliação das ações são peças fundamentais.

Desse modo, a teoria do agir comunicativo constitui-se em um referencial teórico ímpar à construção de uma dimensão humanista e pedagógica na prática biblioteconômica. Pois, por centrar-se em conviçcões intersubjetivamente compartilhadas pelos participantes de uma interação que busca o entendimento sobre algo no mundo, a teoria possibilita a renovação do saber cultural, a integração social e a criação de solidariedade e a formação de identidades sociais.

A construção de uma narrativa educacional na prática do bibliotecário escolar fundada na perspectiva da pedagogia da ação comunicativa favorece o desenvolvimento de uma

[...] práxis emancipatória, humanamente libertadora, pois implica o reconhecimento de cada sujeito como um "outro", distinto e livre possuidor do seu próprio horizonte de sentido. $\mathrm{Na}$ comunicação solidária o outro aparece em sua dignidade própria como alguém que não pode ser reduzido a aspecto ou momento de um sistema qualquer (BOUFLEUR, 2001, p. 87).

Torna-se fundamental que o bibliotecário escolar empreenda ações educativas baseadas na lógica pedagógica da ação comunicativa, uma vez que esta permite desenvolver uma concepção de aprendizagem baseada na relação intersubjetiva entre os 
sujeitos, que é um fator elementar na construção da subjetividade. Nessa concepção de aprendizagem, a construção do conhecimento se processa por meio da compreensão das razões que

[...] justificam algo no mundo como sendo uma feição verdadeira no mundo objetivo, ou como uma norma justa no mundo social, ou ainda como manifestação sincera no mundo subjetivo. O conhecimento da "realidade do mundo", dessa forma, não aparece como um desvelamento de sua pretensa essencialidade, mas como apreensão das relações intersubjetivas que constituem essa realidade (BOUFLEUR, 2001, p. 80).

Roe (1999 apud DUDZIAK, 2001) considera que o domínio da ação do bibliotecário no processo de aprendizagem deve se embasar em quatro conceitos fundamentais relacionados a lógica da ação comunicativa:

- Intencionalidade: quando o bibliotecário direciona a interação e o aprendizado;

- Reciprocidade: todos os atores envolvidos no processo de mediação aprendem;

- Significado: quando a experiência se torna significativa para todos os envolvidos;

- Transcendência: quando a experiência adquirida na aprendizagem é apreendida na vida dos atores.

Entre as práticas baseadas nos pressupostos da ação comunicativa e do discurso que estão sendo desenvolvidas em algumas instituições educacionais, pode-se mencionar as "comunidades de aprendizagem", que objetivam resolver o problema do fracasso escolar envolvendo todos os atores inseridos nesse contexto, inclusive 0 bibliotecário, em uma prática educativa que visa:

[...] estimular, favorecer e desenvolver, o exercício do direito à participação por parte de quem esteja direta ou indiretamente nela implicada, considerando que a deliberação é possível em coletivos que se colocam em disposição para dialogarem na busca pelo entendimento (BRAGA, 2010, p. 8).

Nas comunidades de aprendizagem as relações entre os atores são mediadas pela aprendizagem dialógica que 
[...] se mostra como a mais adequada para responder às novas exigências sociais e educativas da sociedade da informação ao fazer com que a comunidade se envolva na educação das crianças, já que a escola não pode assumir mais toda esta responsabilidade sozinha; ao facilitar a entrada de diversas pessoas e culturas na escola possibilitando aprendizagens mais ricas e variadas; ao estimular o diálogo igualitário entre todos os agentes educativos ante um objetivo comum; ao utilizar o diálogo para aprender mais (potencializam-se as capacidades de seleção e processamento da informação através de um diálogo que gera reflexão) e melhor (aprendizagem com valores: solidariedade, respeito etc.) (BRAGA, 2010, p. 8).

\section{CONSIDERAÇÕES FINAIS}

A crise da racionalidade produtivista vivenciada pela educação em decorrência das novas dinâmicas da sociedade e da economia obriga o bibliotecário escolar a repensar o seu papel e sua atuação nesse contexto em contínua mutação.

A visão tradicional da educação é substituída por um enfoque diferenciado, cuja ênfase está no aprendizado ao longo da vida e no desenvolvimento de habilidades essenciais para manipulação da informação e do conhecimento no ambiente digital. Assim, grandes desafios são impostos à educação, que deve desenvolver uma política pedagógica para formar um coletivo inteligente com habilidades criticas e criativas capaz de participar ativamente de processos sociais, acompanhando as transformações estruturais e tecnológicas, e principalmente, respeitando a pluralidade cultural.

Tendo em vista esses desafios, cabe ao bibliotecário escolar enquanto profissional inserido nesse contexto, repensar o seu agir profissional para adaptar-se às novas mudanças.

Geralmente o bibliotecário é visto como um guardião de livros, um ordenador e detalhista técnico. Do mesmo modo, o bibliotecário parece não ter qualificação pedagógica para agir na biblioteca escolar, e por essa razão a sua função se restringe a organizar o acervo para disponibilização. Por conseguinte, a biblioteca é considerada um grande depósito de livros ou lugar para copiar verbetes. Isto resulta em distância das ações pedagógica desenvolvidas na escola, comprometendo a inserção da biblioteca no contexto educacional como espaço de ensino-aprendizagem.

A proposta apresentada representa esforço inicial para repensar o agir do bibliotecário escolar no processo de ensino-aprendizagem. Devido à complexidade do tema, são necessários novos estudos, que envolvam outros elementos de análise, permitindo avaliações mais detalhadas. Espera-se, contudo, que contribua como sugestão 
de reflexão e debate aos bibliotecários escolares e também incentive o desenvolvimento de uma prática biblioteconômica fundada na racionalidade comunicativa.

\section{REFERÊNCIAS}

ARAGÃO, Lucia Maria de Carvalho. Razão comunicativa e teoria social crítica em Jürgen Habermas. 3. ed. Rio de Janeiro: Tempo Brasileiro, 2006.

BANNELL, Ralph Ings. Habermas \& a educação. Belo Horizonte: Autêntica, 2006.

BORBA, Maria do Socorro Azevedo. Bibliotecário educador: reflexão-ação-reflexão. In: CONGRESSO BRASILEIRO DE BIBLIOTECONOMIA, DOCUMENTAÇÃO E CIÊNCIA DA INFORMAÇÃO, 24., 2011, Maceió. Anais... Maceio, 2011. Disponível em: <http://febab.org.br/congressos/index.php/cbbd/xxiv/paper/view/58>. Acesso em: 27 set. 2012.

BOUFLEUR, José Pedro. Pedagogia da ação comunicativa: uma leitura de Habermas. 3. ed. ljuí: Ed. Unijuí, 2001.

BRAGA, Fabiana Marini. Comunidades de aprendizagem: desenvolvendo uma educação democrática e dialógica com os familiares e o entorno escolar. In: REUNIÃO ANUAL DA ASSOCIAÇÃO NACIONAL DE PÓS-GRADUAÇÃO E PESQUISA EM EDUCAÇÃO, 33., 2010, Caxambu. Anais... Caxambu, 2010. Disponível em:

<http://www.anped.org.br/33encontro/app/webroot/files/file/Trabalhos\%20em\%20PDF/GT 06-6507--Res.pdf>. Acesso em: 27 set. 2012.

CALDIN, Clarice Fortkamp. Reflexões acerca do papel do bibliotecário de biblioteca escolar. Revista ACB: Biblioteconomia em Santa Catarina, Florianópolis, v. 10, n. 2, 2005. Disponível em: <http://revista.acbsc.org.br/racb/article/view/431 >. Acesso em: 19 jun. 2011.

CAMPELLO, Bernardete Santos et al. Situação das bibliotecas escolares no Brasil: o que sabemos? Biblioteca Escolar em Revista, Ribeirão Preto, v. 1, n. 1, p. 1-9, 2012.

Disponível em: <http://revistas.ffclrp.usp.br/BEREV/article/view/101>. Acesso em: 14 out. 2012.

CORRÊA, Elisa Cristina Delfini et al. Bibliotecário escolar: um educador? Revista ACB: Biblioteconomia em Santa Catarina, Florianópolis, v. 7, n. 1, 2002. Disponível em: <http://revista.acbsc.org.br/racb/article/view/379/459>. Acesso em: 22 set. 2012.

\section{DUDZIAK, Elisabeth Adriana. A information literacy e o papel educacional das}

bibliotecas. 2001. 187 f. Dissertação (Mestrado em Ciência da Informação e Documentação) - Escola de Comunicação e Artes da Universidade de São Paulo, São Paulo, 2001. Disponível em: <http://www.teses.usp.br/teses/disponiveis/27/27143/tde30112004-151029/pt-br.php>. Acesso em: 21 ago. 2009. 
FURTADO, Cassia. A biblioteca escolar brasileira no sistema educacional da sociedade da informação. Biblioteca Escolar em Revista, Ribeirão Preto, v. 1, n. 1, p. 1-9, 2012. Disponível em: <http://gebe.eci.ufmg.br/downloads/317.pdf>. Acesso em: 12 mar. 2012.

GONZÁLEZ DE GÓMEZ, Maria Nélida. Habermas, informação e argumentação. In: PINZANI, Alessandro; LIMA, Clóvis; DUTRA, Delamar (Coord.). O pensamento vivo de Habermas: uma visão interdisciplinar. Florianópolis: NEFIPO, 2009. p. 115-138.

HABERMAS, Jürgen. Consciência moral e agir comunicativo. 2. ed. Rio de Janeiro: Tempo Brasileiro, 2003.

Fundamentação lingüística da sociologia: obras escolhidas de Jürgen Habermas. Lisboa: Ed. 70, 2010.

Racionalidade e comunicação. Lisboa: Ed. 70, 1996.

Teoria do agir comunicativo. São Paulo: WMF Martins Fontes, 2012. 2. v.

Verdade e justificação: ensaios filosóficos. São Paulo: Loyola, 2004.

HERMANN, Nadja. Conferência 2: aprendizagem e interpretação. Rio de Janeiro: IBICT, 2012.

INTERNATIONAL FEDERATION OF LIBRARY ASSOCIATIONS AND INSTITUTIONS/ORGANIZAÇÃO DAS NAÇÕES UNIDAS PARA A EDUCAÇÃO, A CIÊNCIA E A CULTURA. Diretrizes IFLA/UNESCO para a biblioteca escolar. São Paulo: IFLA, 2005. Disponível em:<http://www.ifla.org/files/assets/school-librariesresource-centers/publications/school-library-guidelines/school-library-guidelines-pt.pdf> Acesso em: 18 jan. 2013.

KUHLTHAU, Carol Collier. O papel da biblioteca escolar no processo de aprendizagem. In: VIANNA, Márcia Milton; CAMPELLO, Bernadete; MOURA, Victor Hugo Vieira.

Biblioteca escolar: espaço de ação pedagógica. Belo Horizonte: EB/UFMG, 1999. p. 914.

MILANESI, Luis. Biblioteca. São Paulo: Ateliê Editorial, 2002.

MORIGI, Valdir José; BONOTTO, Martha E. K. Kling. A narrativa musical, memória e fonte de informação afetiva. Em Questão, Porto Alegre, v. 10, n. 1, p. 143-161, jan./jun. 2004. Disponível em: <http://seer.ufrgs.br/EmQuestao/article/view/88>. Acesso em: 5 nov. 2012.

MORO, Eliane L. da Silva; ESTABEL, Lizandra Brasil. O encaminhamento da leitura e a magia da biblioteca escolar. Educação em Revista, Porto Alegre, v. 7, n. 40, out. 2003.

Bibliotecas escolares: uma trajetória de luta, paixão e de construção da cidadania. In: MORO, Eliane Lourdes da Silva et al. (Org.). Biblioteca escolar: presente! Porto Alegre: Evangraf, 2011.

PINZANI, Alessandro. Habermas. Porto Alegre: Artmed, 2009.

PRESTES, Nadja Hermann. Educação e racionalidade: conexões e possibilidades de uma razão comunicativa na escola. Porto Alegre: EDIPUCRS, 1996. 
SIEBENEICHLER, Flávio Beno. Jürgen Habermas: razão comunicativa e emancipação. 4. ed. Rio de Janeiro: Tempo Brasileiro, 2003.

SILVA, Ezequiel Theodoro da. Leitura na escola e na biblioteca. 4. ed. Campinas: Papirus, 1993.

SILVA, Waldeck Carneiro da. Miséria da biblioteca escolar. São Paulo: Cortez, 1995.

VÁLIO, Else Benetti Marques. Biblioteca escolar: uma visão histórica. Trans-In-

Formação, Campinas, v. 2, n. 1, 1990. Disponível em: <http://periodicos.puccampinas.edu.br/seer/index.php/transinfo/article/view/1670>. Acesso em: 2 set. 2012.

\title{
Title
}

Discursive action the school librarian

\begin{abstract}
Introduction: The present study weaves some considerations about the library and the professional practice of the school librarian. On this basis, presents reflections about his acting in the teaching-learning process in a perspective communicative-discursive.

Objective: Reflect the practice of the school librarian in the light of the Theories of Communicative action and Discourse of Jürgen Habermas.

Methodology: Bibliographical study of the works of Jürgen Habermas and literature review that focuses on the practice of school librarian.

Results: Due to emergence of a pedagogical and communicative rationality in the practice of school librarian, theories of Jürgen Habermas constitute an important theoretical framework, since they can promote the development of cognitive structures and individual socio-affective, ethics and politics, as well as the creation of solidarity and the formation of social identities allowing the school community ascend to new heights of social integration.

Conclusions: Points to the need for the librarian reflect your practice in the educational environment, considering that this professional is usually seen as the guardian of books, originator and technical detail. Indicates the importance of developing new studies on this theme which involves other elements of analysis thus allowing more detailed assessments.
\end{abstract}

Keywords: School librarian. Habermas. Communicative action. Discourse.

\section{Título}

Acción discursiva la bibliotecaria de la escuela

\section{Resumen}


Introducción: El presente estudio teje algunas consideraciones acerca de la biblioteca y la práctica profesional de la bibliotecaria de la escuela. Sobre esta base, presenta reflexiones sobre su actuación en el proceso de enseñanza-aprendizaje en un perspectiva comunicativo-discursivo.

Objetivo: Reflejar la práctica de la bibliotecaria de la escuela a la luz de las teorías de la acción comunicativa y del discurso de Jürgen Habermas.

Metodología: Estudio bibliográfico de las obras de Jürgen Habermas y revisión de literatura que se centra en la práctica de la bibliotecaria.

Resultados: Debido a la necesidad de una racionalidad comunicativa y pedagógica en la práctica de la bibliotecaria, las teorías de Jürgen Habermas constituyen un marco teórico importante, puesto que puede promover el desarrollo de estructuras cognitivas y cada socio-afectivas, ética y política, así como la creación de la solidaridad y la formación de identidades sociales permitiendo a la comunidad escolar asciende a nuevas alturas de integración social.

Conclusiones: Apunta la necesidad de la bibliotecaria refleja su práctica en el ámbito educativo, teniendo en cuenta que este profesional es generalmente visto como el guardián de libros, autor y detalles técnicos. Indica la importancia de desarrollar nuevos estudios sobre este tema que involucra a otros elementos de análisis, permitiendo así que las evaluaciones más detalladas.

Palabras clave: Bibliotecaria. Habermas. Acción comunicativa. Discurso.

Recebido em: 10.09.2013

Aceito em: 30.11.2013 